\title{
DNA fingerprinting of cultivated and wild genotypes of Curcuma species from agroclimatic regions of Chhattisgarh
}

Akanksha Jain ( $\square$ akankshanakhat@gmail.com )

Guru Ghasidas University

\section{Parag Jain}

Department of Pharmacology, Columbia Institute of Pharmacy, Raipur, Chhattisgarh, India - 493111

\section{Research}

Keywords: ISSR, Genetic diversity, SSR, Curcuma aromatica, Curcuma caesia, Curcuma longa

Posted Date: April 14th, 2020

DOI: https://doi.org/10.21203/rs.3.rs-20321/v1

License: (c) (i) This work is licensed under a Creative Commons Attribution 4.0 International License.

Read Full License 


\section{Abstract}

In the present study we had tried to investigate different genotypes of Curcuma isolated from different agroclimatic zones of Chattisgarh based on molecular fingerprinting as they contain varying range of Curcumin. Genetic fingerprints of 25 genotypes of Curcuma caesia, Curcuma longa and Curcuma aromatica by using 13 and 11 SSR primers. These primers were used to determine the diversity in genes for their proper utilization, genotypic conservation and commercial production of curcuma genotypes. Among all the studied varieties, 13 ISSR and 11SSR primers generated 107 and 51 different amplified fragments, of which $97 \%$ and $86 \%$ showed polymorphism, respectively. Through all the ISSR and SSR primers in all the genotypes amplified 1080 and 567 loci out of which 102 polymorphic and 5 monomorphic alleles were found in ISSR primers. 47 polymorphic and 4 monomorphic alleles were found in SSR. Different ISSR and SSR markers were used to estimate the DNA fingerprinting, genetic similarity and distance among or between the Curcuma genotypes. UPGMA data scoring methods were to analyze the variations between these genotypes of Curcuma. Thus, this study provides a baseline data for conservation of these curcuma genotypes that could be an important research towards optimizing industry level production of Curcumin production.

\section{Introduction}

Plants contain secondary metabolites for their protection that are responsible for different pharmacological properties of the medicinal plants. Especially the medicinal herbs of species Curcuma of family Zingiberaceae is highly valued worldwide for their medicinal and economic significance. Curcuma belongs more than 90 accepted species in the world that includes $\mathrm{C}$. longa named as "Indian Saffron" having wide medicinal value. More than 100 components isolated from rhizomes and leave of turmeric, mainly consisting curcumin, bismethoxycurcumin and desmethoxycurcumin. Curcumin exhibits variety of biological activity including anti-inflammatory agent, colic and chest pains, wound healing, antibacterial, antifungal, anticancer, antioxidant. It is also known for its anti-fertility, neuroprotective, human immunodeficiency virus-1 (HIV-1) and HIV-2 protease inhibitor, antialzheimer, anti-hepatotoxic, immunomodulatory activity and in menstrual difficulties (Rajasekaram, 2011; Seo et al., 2017; Ameruoso et al., 2017). C. caesia locally call as Black turmeric is an uncommon endemic as well as ethno medicinally important plant of south East Asia. Rhizomes of black turmeric have bluish black color and emit a camphorous smell due to presence of essential oil. C. aromatica is commonly known as wild turmeric, kasturimanjal, it is found effective in snake bite, sprain, bruise, inflammation, tonic, carminatives, astringent, antioxidant and for antimicrobial activity (Sikha et al., 2015).

All the three targeted species of turmeric have great demand in increasing demand in the global market due to their medicinal applications. In spite of this no major breakthrough has been noticed in boosting the production of turmeric and increasing the exports. Chhattisgarh, comprising 3 agroclimatic zones, produces $83,470 \mathrm{Mt}$. of turmeric from an area of 9747 ha with an average productivity of $8.56 \mathrm{Mt} / \mathrm{ha}$ which is not satisfactory. The major bottle-neck is the non-availability of requisite high curcumin containing genotypes. Usually turmeric with curcumin content more than $5 \%$ has commercial value. 
Therefore it is imperative to study the extent of variability in curcumin content of different cultivars and accessions of turmeric from different regions of Chhattisgarh so as to select the genotype best suited to each of these regions. Though turmeric displays great morphological and phytochemical diversity, meager information is available on the magnitude of variation in curcumin content among available germplasm of Chhattisgarh. These concerns warrant identification of elite chemotypes of medicinal plant species in order to grown in suitable environments, harvested at appropriate age and time so as to maintain uniformity in the desired chemical constituents. Recently genetic fingerprinting has been proved to be very useful in germplasm characterization i.e. for identification and cloning of important genes and understanding interrelationship at molecular level. It can be used to identify unambiguously a plant variety or clone through different markers.

Thus, the present study was preformed determine genetic proximity between curcuma species collected from three Agro-Climatic Zone of Chhattisgarh which include Bastar Plateau Zone, Chhattisgarh Plain Zone and North Hills Zone, thus originated keeping this in mind the importance of Curcuma species including endemic ones have 25 genotypes from different agroclimatic region of Chhattisgarh using two different sets of molecular markers, viz., SSR, ISSR, respectively

\section{Materials And Methods}

\subsection{Collection and Extraction of DNA from curcuma species}

The species of curcuma was collected different regions of Chhattisgarh, India as shown in Table 1. In these species 25 genotypes of $C$. longa $L$. and $C$. caesia Roxb. were cultivated varieties. However, $C$. aromatica Salibs. varieties were of wild habitant. The protocol for deoxyribonucleic acid (DNA) extraction was as described by Edwards et al. (1991) and Das et al., (2011) with slight modification. Genomic DNA was isolated from frozen leaf samples by grinding with a mortar, pestle in extraction buffer (100 mM Tris$\mathrm{HCl}$ [pH 8.0], $1.4 \mathrm{M} \mathrm{NaCl}, 20 \mathrm{mM}$ EDTA, $2 \%$ SDS) and incubated at $65^{\circ} \mathrm{C}$ for $1 \mathrm{~h}$ in $500 \mu$ l of sodium dodecyl sulphate (SDS) extraction buffer. After extraction with an equal volume of chloroformisoamylalcohol (24:1) and centrifugation at $5000 \mathrm{rpm}$ for $15 \mathrm{~min}$, the upper phase containing DNA was treated with $5 \mu \mathrm{l}(10 \mathrm{mg} / \mathrm{ml})$ RNase for samples to eliminate RNA by incubation at $37^{\circ} \mathrm{C}$ for $15 \mathrm{~min}$. Then again treated with Chloroform:Isoamylalcohol to for removal of nonnucleic acid compounds. Genomic DNA was precipitated out of the upper phase by adding $0.6 \mathrm{vol}$ of chilled ethanol and $100 \mu \mathrm{l}$ of $5 \mathrm{M} \mathrm{NaCl}$ and keeping at less than $4^{\circ} \mathrm{C}$ for several hours. After incubation centrifuge at $10000 \mathrm{rpm}$ for $15 \mathrm{~min}$ and the precipitate was washed several times with $75 \%$ ethanol, and then air-dried and dissolved in appropriate volume of TE buffer (10 $\mathrm{mM}$ Tris-HCl [pH 8.0], $1 \mathrm{mM}$ EDTA). The quality and quantity of the DNA was determined with a Thermo Scientific Nano drop and genomic DNA was also quantified by agarose gel electrophoresis with use of standard lambda DNA as a reference.

\subsection{Primer screening}

31 synthesized inter simple sequence repeat (ISSR) primers (Oligos) or 25 simple sequence repeat (SSR) primers (Bioserve Hyderabad) were initially screened to determine the suitability of each primer for the 
study. Primers were selected for further analysis based on their ability to detect distinct, clearly resolved, and polymorphic amplified products within the genotypes. To ensure reproducibility, the primers generating no, weak, or complex patterns were discarded select only 13 ISSR and 11 SSR primers for further study (Table 2, 3).

\subsection{Genetic diversity analysis by Molecular markers}

Thirteen ISSR primers (Oligos) and Eleven SSR primers (Bioserve, Hyderabad, India) were used for PCR amplification. Based on results, good resolution and reproducibilityability, all ISSR and SSR primers were selected out of several primers utilized during screening. PCRs with a single primer were carried out in a final volume of $20 \mu \mathrm{l}$ Containing (2.5 $\mu \mathrm{l}) 50 \mathrm{ng}$ template DNA, $2 \mu \mathrm{l} 2 \mathrm{mM}$ of dNTP mix (Himedia), $2 \mu \mathrm{l}$ $10 \mathrm{mM}$ of oligonucleotides synthesized primer, $2 \mu \mathrm{l} 1 \mathrm{X}$ Taq buffer and $0.3 \mu \mathrm{l} 2 \mathrm{U}$ Taq DNA polymerase (Thermo fisher). Amplification was performed in a thermal cycler (Eppendorf and Biorad). In ISSR, PCR was performed at an initial temperature of $95^{\circ} \mathrm{C}$ for $5 \mathrm{~min}$ for complete denaturation. The second step consisted of 45 cycles having three ranges of temperature, i.e., at $94^{\circ} \mathrm{C}$ for $1 \mathrm{~min}$ for denaturation of template DNA, primer annealing temperature was set at $2^{\circ} \mathrm{C}$ lower than the melting temperature for $1 \mathrm{~min}$ and at $72^{\circ} \mathrm{C}$ for $2 \mathrm{~min}$ for primer extension, followed by running the samples at $72^{\circ} \mathrm{C}$ for $8 \mathrm{~min}$ for final extension. The PCR products obtained from ISSR were analyzed in $2 \%$ agarose gel stained with $3 \mu \mathrm{l}$ ethidium bromide. PCR products from ISSR markers were combined with $3 \mu$ l of a loading buffer (orange green gel loading dye Himedia and were analyzed directly on $2 \%$ agarose gels in 1X TAE buffer. Electrophoresis was done for about 45 min at 120 volts. 100 bp ladder (Himedia) was used to compare the molecular weights of amplified products. Visualization of the amplified bands was done by gel documentation system BioRad. The detection of microsatellite polymorphism was performed using 5 SSR markers characterized by (Singh, 2015) and 6 different SSR primers. The SSR amplification condition was as follows: an initial hot start and denaturing step at $95^{\circ} \mathrm{C}$ for 5 min followed by 40 cycles of a $1 \mathrm{~min}$ denaturation at $94^{\circ} \mathrm{C}$, a $1 \mathrm{~min}$ annealing based on primer tm, and a $1 \mathrm{~min}$ primer elongation at $72^{\circ} \mathrm{C}$. A final extension step at $72^{\circ} \mathrm{C}$ for 5 min was performed. The PCR amplified products were resolved in a $2 \%$ agarose gel. Electrophoresis was done for about two and half hours at 60 volts. 100 bp ladder (Himedia) was used to compare the molecular weights of amplified products.

\subsection{Data scoring and analysis}

Only clear, unambiguous and reproducible bands were considered for data analysis. Each band was considered to be a single locus. Data were scored as " 1 " for presence and "0"for absence. To avoid taxonomic ambiguities, the intensity of bands was not taken into considerations, only the presence of band was taken as indicative. The binary data of the ISSR and SSR fingerprints were used further for population genetic analyses. The numbers of monomorphic and polymorphic bands were derived from the binary data, and their percentages were calculated. The level of similarity between species was established as the percentage of polymorphic bands, and a matrix of genetic similarity was compiled using Jaccard's similarity coefficient (JSI) (Jaccard, 1908). Similarity coefficients were used to construct the dendrogram using the unweighted pair group method with arithmetic average (UPGMA) and the 
sequential hierarchical and nested clustering routine in the Past 3 software representing genetic relationship between 25 genotypes of Curcuma species. 9 genotypes of Curcuma longa, 10 genotypes of Curcuma caesia and 6 genotypes of Curcuma aromatica. The polymorphism information content (PIC) for each ISSR and SSR marker was calculated with the formula described by Roldan-Ruiz et al. 2006; ZhiHui Guoet al., 2014; Jain et al., 2019). PICi= 2fi $(1-f i)$ where PICi is the polymorphic information content of markeri, $\mathrm{fi}$ the frequency of the marker bands which were present, and $(1-\mathrm{fi})$ the frequency of marker bands which were absent. Other basic parameters for genetic diversity were calculated in the POPGENE application. The the number of different alleles (na), the mean number of effective alleles (ne)No. of Effective Alleles $=1 /\left(p^{\wedge} 2+q^{\wedge} 2\right)$, and the Shannon Information index was calculated by formula I $==-1^{*}$ $(p * \operatorname{Ln}(p)+q * \operatorname{Ln}(q))$ index $(I), \mathrm{He}=$ Expected Heterozygosity $=2 * p * q$ and uHe = Unbiased Expected Heterozygosity $=(2 \mathrm{~N} /(2 \mathrm{~N}-1)) *$ He were calculated by above mentioned formula Where for Diploid Binary data and assuming Hardy-Weinberg Equilibrium, $q=(1-\text { Band Freq. })^{\wedge} 0.5$ and $p=1-q$.

\section{Results}

\subsection{Quality of extracted DNA samples}

Extracted genomic DNA of Curcuma genotypes was quantified by Nano drop system anintegrity of DNA on $0.8 \%$ agarose gel is shown in Fig. 1 .

\subsection{ISSR polymorphism}

The ISSR derived banding pattern is presented in Fig. 2. Thirteen ISSR primers were used to characterize the genetic diversity present among the genotypes of Curcuma species (Table 2). Thirteen of these primers showed a total of 102 polymorphic reproducible fragments that ranged from 250-2000 bp in size. High percentage of polymorphism was displayed in 10 primers (100\%) other all the 3 primers showed IG10 (78\%), IG-14 86\% and UBC-812 (71\%) of polymorphism among all three species of Curcuma. Total of 102 polymorphic bands and 5 monomorphic bands were detected (Table 4). The percentage of ISSR polymorphism for different Curcuma species studied ranged from 71 to $100 \%$. The PIC values for ISSR primers ranged from $0.44-0.5$ with an average of 0.48 of all the primers. The primer UBC-811 and UBC841 produced maximum number of 11 bands, while the primer IG-2, B17898 and UBC-836 resulted in amplification of only 6 bands. Among these ISSR primers, minimum PIC was found to be 0.44 in IG-03.

\subsection{SSR polymorphism}

Eleven SSR primers will be amplified and showed diversity so we choose only these out of 25 synthetic oligos (Table 3). The primer combinations had amplified 51 loci among which 4 were found to be monomorphic in nature and the rest were polymorphic (Fig 4a, 4b and Table 6). Maximum number of 9 bands was resolved for the primer CIR-343 and the minimum 1 for CIR-375. Maximum number of polymorphism was found in primer CIR-263, CIR-343, Cumisat-22(100\%) and minimum in primer Cumisat27 (50\%). The average PIC of all the primers was 0.43 . Bands resolved between 400 to 50 bp were consider for the present investigation. 


\subsection{Data scoring and Cluster analysis}

The dendrogram constructed through UPGMA algorithm using Jaccard's similarity coefficient of ISSR and SSR by using Past 3 software. Dendrogram cluster analysis is an explorative analysis that tries to identify structures within the data it is also known as taxonomy analysis. Cluster analysis is used to identify groups of cases if the grouping is not previously known. In ISSR matrix of Curcuma species shown that it has been divided the dendrogram in two main clusters with 25 genotypes. Jaccard's coefficient showed the genotypes and species closeness with a similarity value 0.94 and distance value 0.81 . Genetic variation of ISSR primers among the genotypes is presented in Table 5. Constructed dendrogram, is shown in Fig. 3. In another extent the variation in SSR primers among the genotypes and Jaccard's coefficient by UPGMA algorithm showed that the species were most closely related with a similarity value 0.91 and distance value 0.77 . Genetic variations in SSR primers among all the Curcuma genotypes is presented in Table 7 and dendrogram tree of SSR marker is presented in Fig. 5.

\section{Discussion}

Dendrogram constructed on the basis of different ISSR primers with their respective genotypes genotypes was divided into the two groups, first group contained 5 genotypes of Curcuma caesia and second group contained remaining of the genotypes of all Curcuma species. The second cluster was again divided into two sub-clusters and it was divided into again four sub cluster were consisting of Curcuma longa and Curcuma aromatica because these are much similar species but Curcuma caesia and Curcuma aromatica have also show more similary to each other so rest of the subclusters containing genotypes of Curcuma caesia and Curcuma aromatica. As same ISSR primers similarity is clearly seen in dendrogram and it has been divided into 2 main groups with two sub clusters. Second small cluster contain few genotypes due to genetic difference to the other genotypes. Correlation between individual genotypes to each other is significant. Archana Das et al.,(2011) to provide frame work for large scale production and cultivation of best genotypes Mohanty et al., 2014; Ashwani Kumar Singh et al., 2015.

In SSR distance matrix of Curcuma species shown that it has been divided the dendrogram in three main clusters then again it has to be divided into number of sub clusters due to the presence of greater polymorphism exhibited in between genotypes of wild and cultivated varieties of Curcuma species due to lots of environmental, soil, agroclimatic and its genetic makeup. SSR primers dendrogram plot shown that Curcuma longa genotypes form again different subcluster due to minor changes in its genetic sequence and one genotype of Curcuma caesia ICC place in single sub cluster in their group because it showed unique bands in most of the SSR primers which have not present at all.

\section{Conclusion}

This study provides a baseline data for conservation of these curcuma genotypes that could be an important research towards optimizing industry level production of Curcumin production. 


\section{Abbreviations}

HIV - Human immunodeficiency virus

DNA - Deoxyribonucleic acid

SDS - Sodium dodecyl sulphate

ISSR - Inter simple sequence repeat

SSR - Simple sequence repeat

UPGMA - Unweighted pair group method with arithmetic average (

PIC - Polymorphism information content

\section{Declarations}

Ethics approval and consent to participate - No animals and humans were included in the study.

Consent for publication - Not applicable.

Availability of data and materials - It can be made available on request.

Competing interests - There is no competing interest.

Funding - No funding was received.

Authors' contributions - AK performed laboratory work, PJ drafted the manuscript.

Acknowledgements - Authors are thankful to the Department of Biotechnology, Guru Ghasidas Vishwavidyalaya Bilaspur (A Central University) to provide infrastructure and financial aid. Authors are also thankful to Aditya Biotech lab \& Research Pvt. Ltd, Raipur (C.G.) for providing the lab facilities and experimental guidance.

\section{References}

Apavatjrut P, Somboon A, Puangpen S and Chiara A (1999). Molecular markers in the identification of some early flowering Curcuma L. (Zingiberaceae) species. Ann. Bot. 84: 529-534.

Barakat MN, Abdel Fattah RS, Badr M and El-Torky MG (2010). In vitro mutagenesis and identification of new variants via RAPD markers for improving Chrysanthemum morifolium. Afr. J. Agri. Res. 8: 748-757.

Corcolon EA, Laurena AC, Dionisio-sese ML. (2015). Genotypic Characterization of Turmeric ( Curcuma longa L .) Accessions from Mindanao , Philippines Using RAPD Markers. Procedia Chem.;14:157-163. 
doi:10.1016/j.proche.2015.03.023.

Das A, Kesari V, Satyanarayana V M., Parida A, Rangan L. (2011) Genetic Relationship of Curcuma Species from Northeast IndiaUsing PCR-Based Markers Mol Biotechnol 49:65-76

Dreisigacker S, Zhang P, Warburton ML, Skovmand B, Hoisington D, Melchinger AE (2005) Genetic diversity among and within CIMMYT wheat landrace accessions investigated with SSRs and implications for plant genetic resources management. Theor Appl Genet 101(1-2):653

Islam MA, Meister A, Schubert V, Kloppstech K, Esch E et al (2007) Genetic diversity and cytogenetic analysis in Curcuma zedoaria (Christm.) Roscoe. from Bangladesh. Genet Resour Crop Evol 54:149-156

Jatoi SA, Kikuchi A, Yi SS, Naing KW, Yamanaka S, Junko A et al (2006) Use of SSR markers as RAPD markers for genetic diversity analysis in Zingiberaceae. Breed Sci 56:107-111.

Jiang H, Xie Z, Koo HJ, Mclaughhn SP, Timmermann BN, Gang DR et al (2006) Metabolic profiling and phylogenetic analysis of medicinal Zingiber species tools for authentication of gingers (Zingiber officinale). Phytochemistry 67:1673-1685

Lapitan VC, Brar DS, Abe T and Redona ED (2007). Assessment of genetic diversity of Philippine rice cultivars carrying good quality traits using SSR markers. Breed. Sci. 57: 263-270.

Lee SY, Fai WK, Zakaria M, Ibrahim H, Othman RY, Gwag JG, Rao VR, Park YJ et al (2007) Characterization of polymorphic microsatellite markers, isolated from ginger (Zingiber officinale Rosc.). Mol Ecol Notes 7:1009-1011.

Mohanta S, Pk S, Sial P, Gr R.(2015) Morphological and Molecular Screening of Turmeric ( Curcuma longa L .) Cultivars for Resistance against Parasitic Nematode Meloidogyne incognita. Plant Pathology \& Microbiology;6. doi:10.4172/2157-7471.1000270.

Mohanty S, Panda MK, Acharya L, NayakS (2014) Genetic diversity and gene differentiation among ten species of Zingiberaceae from Eastern India.3 Biotech 4:383-390 2014:383-390.

1. Prashanth, A. Yugander and N. Lakshmi Bhavani. (2015) DNA Isolation and PCR Amplification of Turmeric Varieties from Telangana State Int.J.Curr.Microbiol.App.Sci 4(5): 485-490

Naik PK, Alam MA, Singh H, Goyal V, Parida S, Kalia S, Mohapatra T et al (2010) Assesment of genetic diversity through RAPD, ISSR and AFLP markers in Podophyllum hexandrum: a medicinal herb from northeastern Himalayan region. Physiol Mol Biol Plant 16(2):145-148

Noli E, Cont S, Maccaferi M, Sanguineti MC et al (1997) Molecular characterization of Tomato cultivars. Seed Sci Technol 27:1-10 
Nowbuth P, Khittoo G, Bahorun T and Venkatasamy S (2005). Assessing genetic diversity of some Anthurium andraeanum Hort. cut-flower cultivars using RAPD Markers. Afr. J. Biotech. 4: 1189-1194.

Paisooksantivatana, Y., Kako, S., \& Seko, H. (2001). Genetic diversity of Curcuma alismatifolia Gagnep (Zingiberaceae) in Thailand as revealed by allozyme polymorphism. Genetic Resources and Crop Evolution, 48, 459-465.

Paramasivam, M., Poi, R., Banerjee, H., \& Bandyopadhyay, A. (2009). High-performance thin layer chromatographic method for quantitative determination of curcuminoids in Curcuma longa germplasm. Food Chemistry, 113, 640-644.

Policegoudra, R. S., \& Aradhya, S. M. (2008). Biochemical changes and antioxidant activity of mango ginger (Curcuma amada Roxb.) rhizomes during post harvest storage at different temperatures. Postharvest Biology and Technology, 46, 189-194.

Roldán-Ruiz, I.; Dendauw, J.; Van Bockstaele, E.; Depicker, A.; de Loose, M. (2000) AFLP markers reveal high polymorphic rates in ryegrasses (Lolium spp.). Mol. Breed., 6, 125-134.

Sharma A, Namedo AG, Mahadik KR (2008) Molecular markers: net prospects in plant genome analysis. Pharmacogn Rev 2(3):23-34

Singh A K, Nanda P, Singh A and SinghB (2015) Genetic Diversity Analysis in Turmeric (Curcuma Longa L.) Based on SSR Markers Journal of Biological Engineering Research and Review; 2(1): 20-24

Syamkumar, S., \& Sasikumar, B. (2007). Molecular marker based genetic diversity analysis of Curcuma species from India. Scientia Horticulturae, 112, 235-241.

Taheri S, Abdullah TL, Abdullah NA and Ahmad Z (2012). Genetic relationships among five varieties of Curcuma alismatifolia (Zingiberaceae) based on ISSR markers. Genet. Mol. Res. 11: 3069-3076.

Tian HL, Chen XQ, Wang JX and Xue JH (2008). Development and characterization of microsatellite loci for lotus (Nelumbo nucifera). Conserv. Genet. 9: 1385-1388.

Williams JKF, Kubelik AR, Livak KG, Rafalki JA, Tingey SV et al (1990) DNA polymorphisms amplified by arbitrary primers are useful as genetic markers. Nucl Acids Res 18:6531-6535.

Zeitkiewicz E, Rafalski A, Labuda D et al (1994) Genome finger printing by simple sequence repeat (SSR)anchored PCR amplification. Genomics 20:176-183

Zhou, X., Zhangwan, L., Liang, G., Zhub, J., Wang, D., \& Cai, Z. (2007). Analysis of volatile components of Curcuma sichuanensis X. X. Chen by gas chromatography-mass spectrometry. Journal of Pharmaceutical and Biomedical Analysis, 43, 440-444. 
Zhi-Hui Guo, Kai-Xin Fu, Xin-Quan Zhang, Shi-Qie Bai, Yan Fan, Yan Peng, Lin-Kai Huang , Yan-Hong Yan , Wei Liu and Xiao Ma , (2014) Molecular Insights into the Genetic Diversity of Hemarthria compressa Germplasm Collections Native to Southwest China Molecules 2014, 19, 21541-21559.

\section{Tables}

Table: 1 List of Genotypes collected from different regions of Chhattisgarh

\begin{tabular}{llll}
\hline S.no & Accession code & \multicolumn{1}{c}{ Sampling site } & \multicolumn{1}{c}{ Species } \\
\hline 1 & DH & Dongargaon & Curcuma longa $L$. \\
2 & NH & Navagaon & Curcuma longa $L$. \\
3. & LBH & Lakshman Bharda & Curcuma longa $L$. \\
4. & GH & Ganeri & Curcuma longa $L$. \\
5. & MH & Margaon & Curcuma longa $L$. \\
6. & BNH & Bannavagaon & Curcuma longa $L$. \\
7. & GGH & Sarguja & Curcuma longa $L$. \\
8. & UH & Udhyaniki, koni. Bilaspur & Curcuma longa $L$. \\
9. & JH & Jagdalpur & Curcuma longa L. \\
10. & BK & Bargaon & Curcuma caesia Roxb. \\
11. & LK & Laxman Bharda & Curcuma caesia Roxb. \\
12. & CK & Chiddo & Curcuma caesia Roxb. \\
13. & ANK & Andi, Balod & Curcuma caesia Roxb. \\
14. & AK & Acholi & Curcuma caesia Roxb. \\
15. & BNK & Bendarkatta & Curcuma caesia Roxb. \\
16. & GGK & Sarguja & Curcuma caesia Roxb. \\
17. & ICC & IGKV, Koni Bilaspur & Curcuma caesia Roxb. \\
18. & RK & Ratanpur Bilaspur & Curcuma caesia Roxb. \\
19. & JK & Jagdalpur & Curcuma caesia Roxb. \\
20. & JA & Jamsarar & Curcuma aromatica Salibs. \\
21. & ABJA & Aaybhandha beet & Curcuma aromatica Salibs \\
22. & BA & Bargaon & Curcuma aromatica Salibs \\
23. & GGA & Sarguja & Curcuma aromatica Salibs \\
24. & ICA & IGKV, Bilaspur & Curcuma aromatica Salibs \\
25. & GJA & Jagdalpur & Curcuma aromatica Salibs \\
\hline & & & \\
& &
\end{tabular}

Table 2 Sequences and nucleotide length of primers used in the ISSR analysis 


\begin{tabular}{lll}
\hline ISSR Code & \multicolumn{1}{c}{ Sequence } & Tm $^{\circ}$ C \\
\hline IG-03 & GAGGGTGGAGGATC & 50.6 \\
IG-10 & AGAAGAGAGAGAGAGC & 49.2 \\
IG-05 & GACAGACAGACAGACA & 49.2 \\
IG-01 & AGGGCTGGAGGAGGGC & 59.4 \\
IG14 & GAGAGAGAGAGAGAGT & 49.2 \\
IG-02 & AGAGGTGGGCAGGTGG & 56.9 \\
B17898 & CACACACACACAGG & 44.7 \\
B17899 & CTCTCTCTCTCTCTCTTG & 47.7 \\
UBC-807 & AGAGAGAGAGAGAGAGT & 50.4 \\
UBC-811 & GAGAGAGAGAGAGAGAC & 52.8 \\
UBC-836 & AGAGAGAGAGAGAGAGYA & 52.6 \\
UBC-841 & GAGAGAGAGAGAGAGAYC & 54.8 \\
UBC 812 & GAGAGAGAGAGAGAGAA & 50.4 \\
\hline
\end{tabular}

Table 3 Sequences and nucleotide length of primers used in the ISSR analysis

\begin{tabular}{clll}
\hline S.No & ssR Code & Forward & Reverse \\
\hline 1 & CuMiSat -19 & CATGCAAATGGAAATTGACAC & TGATAAATTGACACATGGCAGTC \\
2 & CuMiSat -20 & CGATACGAGTCCATCTCTTCG & CCTTGCTTTGGTGGCTAGAG \\
3 & CuMiSat -22 & AATTTATTAGCCCGGACCAC & AAGAAAGTGAGTAGAAACCAAAGC \\
4 & CuMiSat -26 & CATTCCGATGAATTGTATG & GCAGTTGTTTTGCTTCAG \\
5 & CuMiSat -27 & TATAGATAGCCATGCTGAAG & CCATTTTAGTTCATTACGTG \\
6 & CIR-104 & GAGAGCATTTGATTCCTT & GAACTGCTAACACCACCT \\
7 & CIR-114 & TTGTAATGGAACTTTGGTC & GGTGAGTAAATAAACGGG \\
8 & CIR-165 & ATAAGTGGAGACAGGCA & GACCAGCACAGGAAAC \\
9 & CIR-263 & ACAGATGATGGATGGATAG & TTCAGGAGTTCAGCGT \\
10 & CIR-343 & CCAACAAGACCGACA & GAGGGTGAAAGAGAGAGA \\
11 & CIR-375 & CCAAAATTAGGTGCGTGT & TAAAAGTTGAACATCCTACG \\
\hline
\end{tabular}

Table 4 List of selected informative ISSR primers with percentage of polymorphic bands (\%) and their polymorphic information content (PIC). 


\begin{tabular}{|c|c|c|c|c|c|c|}
\hline S.No & $\begin{array}{l}\text { ISSR } \\
\text { primers }\end{array}$ & $\begin{array}{l}\text { Total no of } \\
\text { band }\end{array}$ & $\begin{array}{l}\text { Total no of } \\
\text { Polymorphic band }\end{array}$ & $\begin{array}{l}\text { Total no of } \\
\text { Monomorphic band }\end{array}$ & $\begin{array}{l}\% \\
\text { polymorphism }\end{array}$ & PIC \\
\hline 1 & IG-03 & 7 & 7 & 0 & $100 \%$ & 0.44 \\
\hline 2 & IG-10 & 9 & 7 & 2 & $78 \%$ & 0.50 \\
\hline 3 & IG-05 & 8 & 8 & 0 & $100 \%$ & 0.49 \\
\hline 4 & IG-01 & 10 & 10 & 0 & $100 \%$ & 0.48 \\
\hline 5 & IG-02 & 6 & 6 & 0 & $100 \%$ & 0.50 \\
\hline 6 & IG14 & 7 & 6 & 1 & $86 \%$ & 0.45 \\
\hline 7 & UBC 812 & 7 & 5 & 2 & $71 \%$ & 0.50 \\
\hline 8 & UBC-807 & 10 & 10 & 0 & $100 \%$ & 0.47 \\
\hline 9 & UBC-811 & 11 & 11 & 0 & $100 \%$ & 0.49 \\
\hline 10 & UBC-836 & 6 & 6 & 0 & $100 \%$ & 0.50 \\
\hline 11 & UBC-841 & 11 & 11 & 0 & $100 \%$ & 0.50 \\
\hline 12 & B17898 & 6 & 6 & 0 & $100 \%$ & 0.50 \\
\hline \multirow[t]{2}{*}{13} & В17899 & 9 & 9 & 0 & $100 \%$ & 0.45 \\
\hline & Total & 107 & 102 & 5 & $95 \%$ & 0.48 \\
\hline
\end{tabular}

Table 5 Genetic variation of Curcuma genotypes in different ISSR primers. 


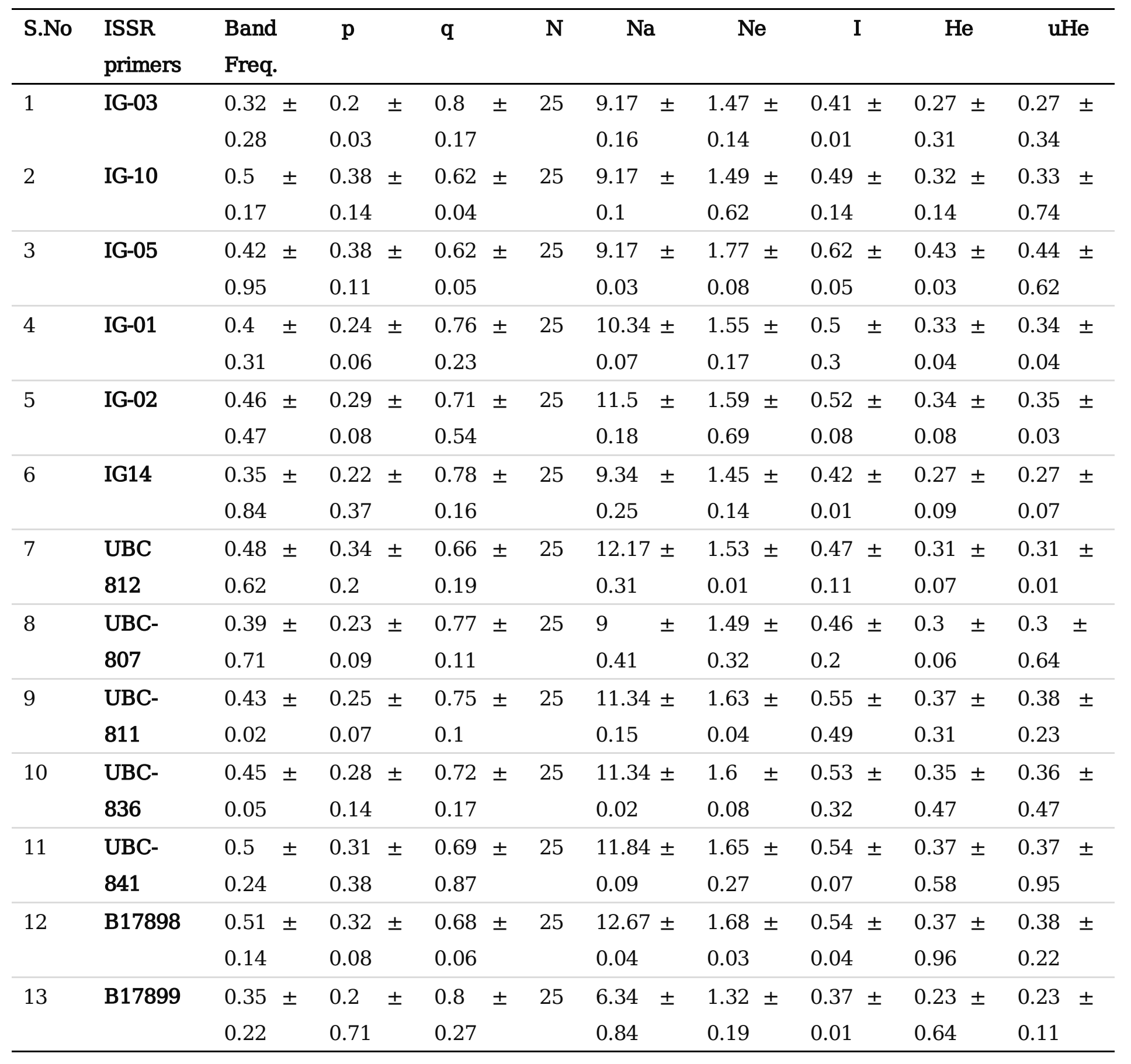

Table 6 List of selected informative SSR primers with percentage of polymorphic bands (\%) and their polymorphic information content (PIC). 


\begin{tabular}{|c|c|c|c|c|c|c|c|}
\hline $\begin{array}{l}\text { S. } \\
\text { No. }\end{array}$ & Marker & $\begin{array}{l}\text { Molecular wt. of } \\
\text { amplified product }\end{array}$ & $\begin{array}{l}\text { total } \\
\text { band }\end{array}$ & $\begin{array}{c}\text { Polymorphic } \\
\text { band }\end{array}$ & $\begin{array}{l}\text { Monomorphic } \\
\text { band }\end{array}$ & $\begin{array}{c}\% \\
\text { polymorphism }\end{array}$ & PIC \\
\hline \multirow[t]{2}{*}{1} & CuMiSat & $200-260$ & 5 & 5 & 0 & $100 \%$ & 0.49 \\
\hline & -19 & & & & & & \\
\hline \multirow[t]{2}{*}{2} & CuMiSat & $170-250$ & 4 & 4 & 0 & $100 \%$ & 0.49 \\
\hline & -20 & & & & & & \\
\hline \multirow[t]{2}{*}{3} & CuMiSat & $200-240$ & 6 & 6 & 0 & $100 \%$ & 0.5 \\
\hline & -22 & & & & & & \\
\hline \multirow[t]{2}{*}{4} & CuMiSat & $150-250$ & 6 & 6 & 0 & $100 \%$ & 0.46 \\
\hline & -26 & & & & & & \\
\hline \multirow[t]{2}{*}{5} & CuMiSat & $180-230$ & 2 & 1 & 1 & $50 \%$ & 0.49 \\
\hline & -27 & & & & & & \\
\hline 6 & CIR-104 & & 3 & 2 & 1 & $67 \%$ & 0.48 \\
\hline 7 & CIR-114 & & 2 & 1 & 1 & $50 \%$ & 0.48 \\
\hline 8 & CIR-165 & & 6 & 5 & 1 & $83 \%$ & 0.43 \\
\hline 9 & CIR-263 & $50-500$ & 7 & 7 & 1 & $100 \%$ & 0.5 \\
\hline 10 & CIR-343 & & 9 & 9 & 0 & $100 \%$ & 0.47 \\
\hline 11 & CIR-375 & & 1 & 1 & 0 & $100 \%$ & 0 \\
\hline
\end{tabular}

Table 7 Genetic variation of Curcuma genotypes in different SSR primers.

\begin{tabular}{ccccccccccc}
\hline 3. No. & SSR Marker & Band Freq. & $\mathbf{p}$ & $\mathbf{q}$ & $\mathbf{N}$ & $\mathbf{N a}$ & $\mathbf{N e}$ & $\mathbf{I}$ & $\mathrm{He}$ & $\mathbf{u H e}$ \\
\hline 1 & CuMiSat -19 & 0.42 & 0.25 & 0.76 & 25 & 10.4 & 1.58 & 0.53 & 0.35 & 0.35 \\
2 & CuMiSat -20 & 0.58 & 0.4 & 0.61 & 25 & 14.5 & 1.64 & 0.54 & 0.36 & 0.37 \\
\hline 3 & CuMiSat -22 & 0.51 & 0.33 & 0.67 & 25 & 12.83 & 1.64 & 0.55 & 0.37 & 0.38 \\
\hline 4 & CuMiSat -26 & 0.36 & 0.21 & 0.8 & 25 & 9 & 1.48 & 0.49 & 0.31 & 0.32 \\
\hline 5 & CuMiSat -27 & 0.58 & 0.55 & 0.46 & 25 & 2.5 & 1.09 & 0.15 & 0.08 & 0.08 \\
\hline 6 & CIR-104 & 0.41 & 0.3 & 0.7 & 25 & 10.33 & 1.35 & 0.37 & 0.23 & 0.24 \\
\hline 7 & CIR-114 & 0.6 & 0.44 & 0.56 & 25 & 15 & 1.52 & 0.52 & 0.34 & 0.34 \\
\hline 8 & CIR-165 & 0.32 & 0.22 & 0.78 & 25 & 8 & 1.29 & 0.33 & 0.13 & 0.13 \\
\hline 9 & CIR-263 & 0.45 & 0.28 & 0.72 & 25 & 11.43 & 1.57 & 0.53 & 0.35 & 0.36 \\
\hline 10 & CIR-343 & 0.38 & 0.23 & 0.77 & 25 & 7.57 & 1.39 & 0.39 & 0.24 & 0.25 \\
\hline 11 & CIR-375 & 0.88 & 0.65 & 0.35 & 25 & 22 & 1.83 & 0.41 & 0.46 & 0.46 \\
\hline
\end{tabular}




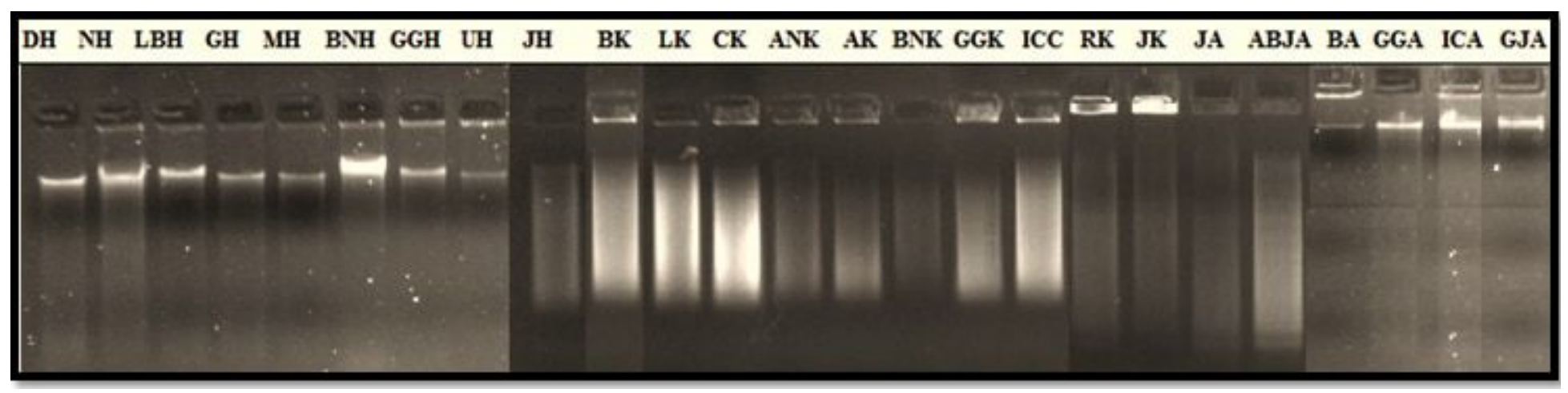

Figure 1

Integrity of isolated Genomic DNA of Curcuma genotypes on $0.8 \%$ agarose gel

L DH NH LBH GH MH BNHGGHUH JH BK LK CK ANK AK BNK GGK ICC RK JK IAABJA BA GGAICA GLA L

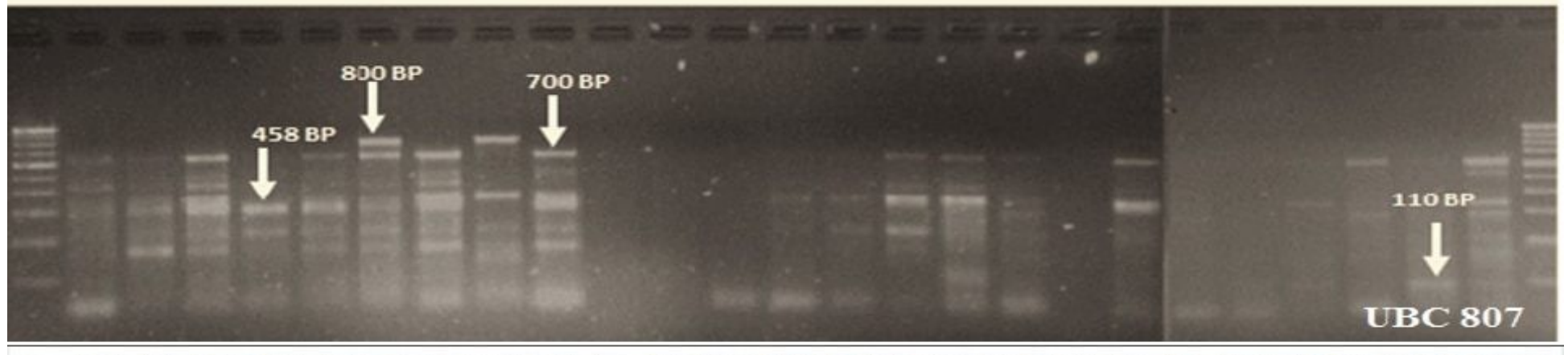

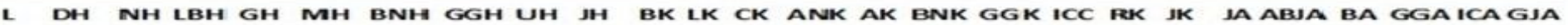
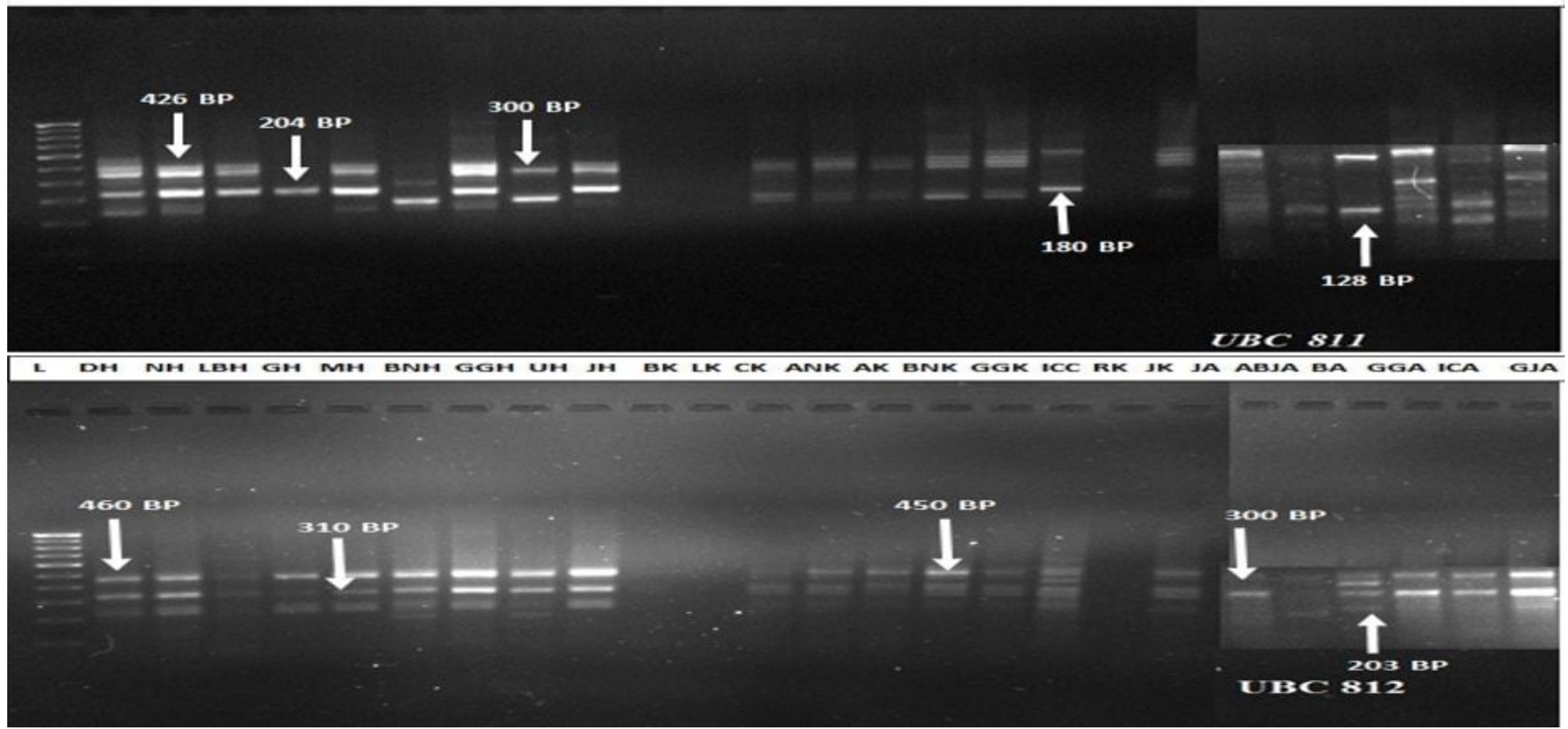

Figure 2

Banding patterns of ISSR fragments of 25 genotypes of three targeted Curcuma species 


\section{Similarity}

\begin{tabular}{|c|c|c|c|c|c|c|c|c|}
\hline ㅇ & 0 & $\varnothing$ & 0 & 0 & 0 & O & 0 & $O$ \\
\hline$\vec{\imath}$ & $N$ & $w$ & 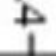 & in & o) & 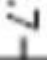 & o) & io \\
\hline
\end{tabular}

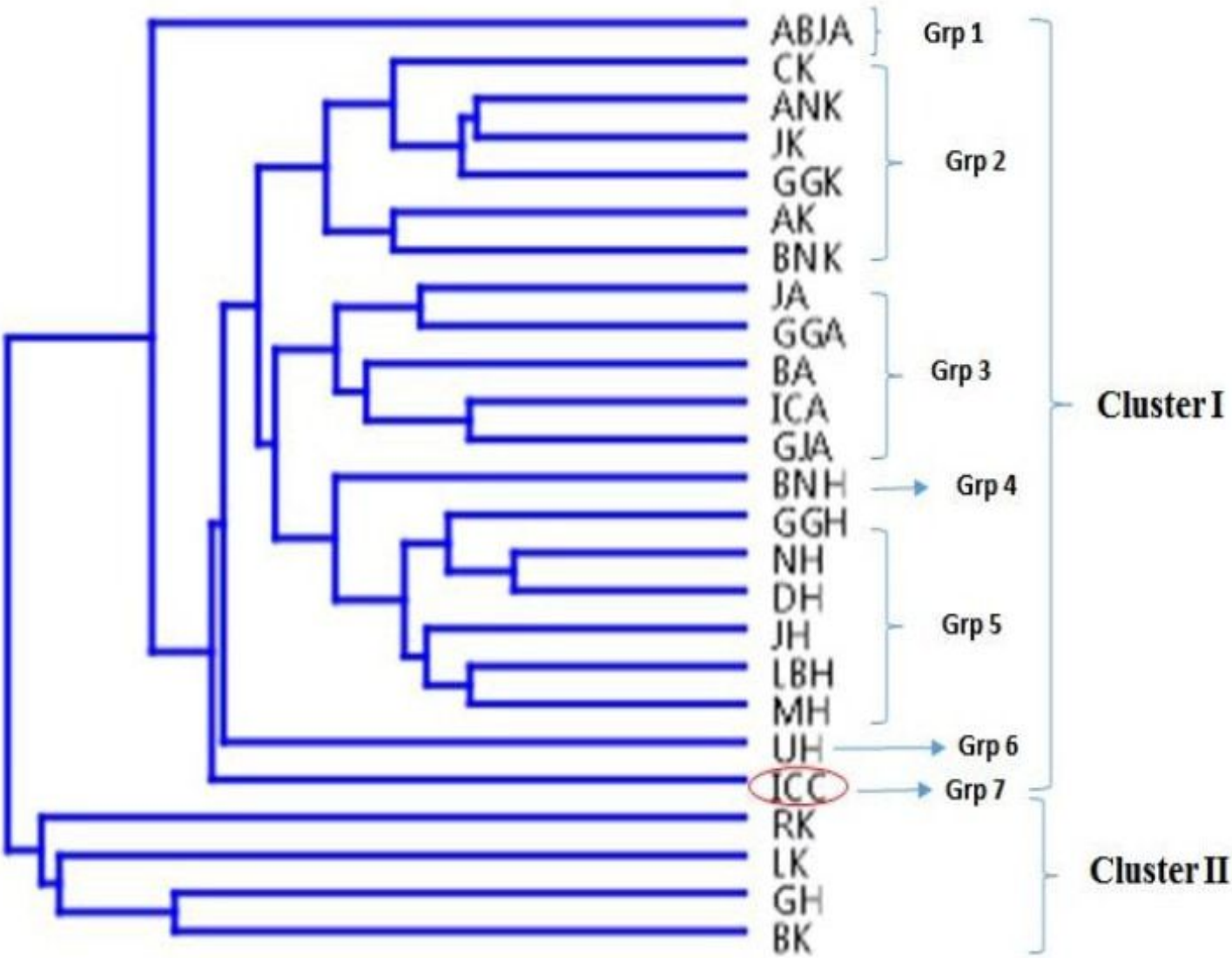

\section{Figure 3}

Dendrogram showing clustering of 25 genotypes of Curcuma species constructed by using UPGMA cluster analysis of genetic similarity based on ISSR data by Jaccard similarity matrix (0.9434)
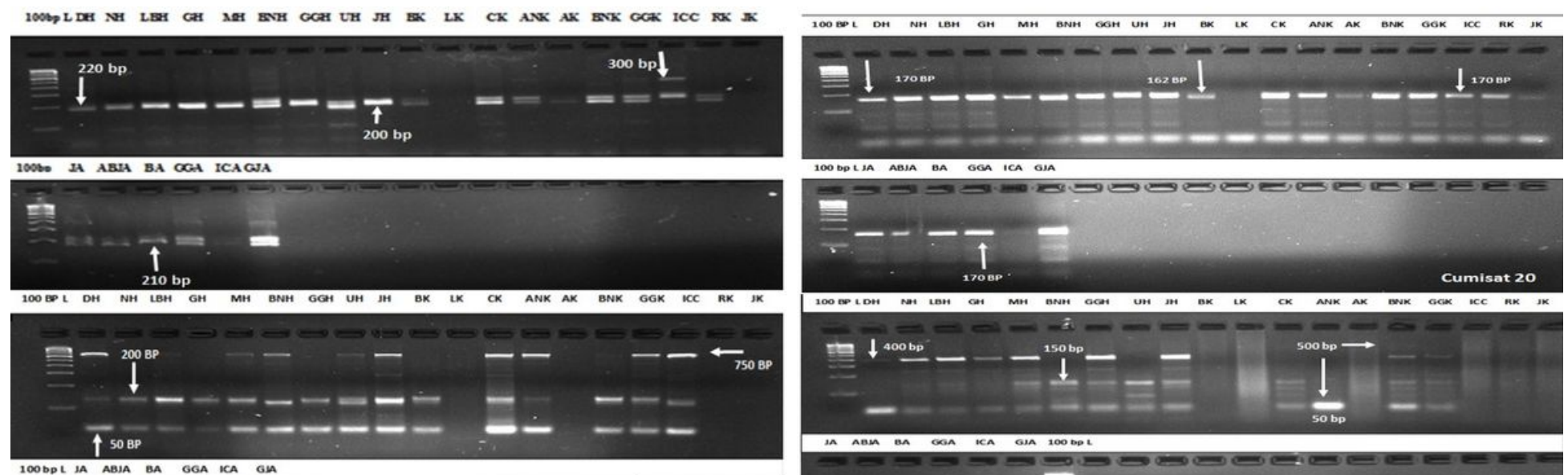

$100 \mathrm{BPL}$ IA ABIA BA GGA ICA GA
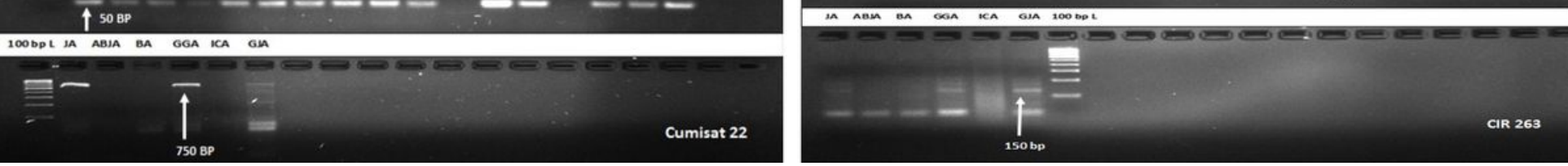


\section{Figure 4}

Figure 4a. Banding patterns of SSR fragments of 25 genotypes of three targeted Curcuma species Figure 4b. Banding patterns of 25 genotypes of three targeted Curcuma species 